Check for updates

Cite this: Chem. Sci., 2019, 10, 4775

๑ All publication charges for this article have been paid for by the Royal Society of Chemistry

Received 2nd February 2019

Accepted 26th March 2019

DOI: $10.1039 / c 9 s c 00595 a$

rsc.li/chemical-science

\section{Direct conversion of phenols into primary anilines with hydrazine catalyzed by palladium $\dagger$}

\begin{abstract}
Zihang Qiu, (D) Leiyang Lv, (D) Jianbin Li, (D) Chen-Chen Li (D) and Chao-Jun Li (D) *
Primary anilines are essential building blocks to synthesize various pharmaceuticals, agrochemicals, pigments, electronic materials, and others. To date, the syntheses of primary anilines mostly rely on the reduction of nitroarenes or the transition-metal-catalyzed Ullmann, Buchwald-Hartwig and Chan-Lam cross-coupling reactions with ammonia, in which non-renewable petroleum-based chemicals are typically used as feedstocks via multiple step syntheses. A long-standing scientific challenge is to synthesize various primary anilines directly from renewable sources. Herein, we report a general method to directly convert a broad range of phenols into the corresponding primary anilines with the cheap and widely available hydrazine as both amine and hydride sources with simple $\mathrm{Pd} / \mathrm{C}$ as the catalyst.
\end{abstract}

Primary anilines, as the parent molecules of aromatic amines, are vital and well exploited building blocks towards a wide range of pharmaceuticals, agrochemicals, plastics, electronic materials, dyes and resins. ${ }^{1}$ Due to their importance, various methods have been explored to synthesize primary anilines. The nitro-reduction or the Ullmann, Buchwald-Hartwig and ChanLam cross-coupling reactions represent the very successful methods to build primary anilines nowadays. However, in most cases, such methods rely on the starting materials derived from non-renewable petroleum based chemicals (BTX, benzene, toluene, xylenes etc.), ${ }^{2}$ in which extra pre-functionalization steps of arenes by nitration, ${ }^{3}$ halogenation ${ }^{4}$ and borylation ${ }^{5}$ are required to generate the corresponding aromatic nitro compounds, arylhalides and arylboron compounds in order to form primary anilines (Scheme $1 \mathrm{a}$ and $\mathrm{b})^{1 \boldsymbol{1 c , 6}}$. On the other hand, naturally abundant phenols, which constitute some of the main units of lignin bio-mass and are widely obtainable at very low cost from coal and cumene industrial processes, are often considered as the alternative renewable aromatic feedstocks. ${ }^{7}$ Because of their sustainable feature, it is highly desirable to develop a method to directly convert phenols into primary anilines.

To this end, only gas-phase direct amination of phenol into aniline was successful, however, under very harsh conditions, in which phenol was vaporized to gas and then reacted with a large excess amount of ammonia and hydrogen gases at very high temperature $\left(>250{ }^{\circ} \mathrm{C}\right) .^{7 d, 8}$ Recently, a liquid phase phenol to aniline transformation was reported, but still requiring high

Department of Chemistry and FQRNT Centre for Green Chemistry and Catalysis, McGill University, 801 Sherbrooke St. W., Montreal, Quebec H3A OB8, Canada. E-mail: cj.li@mcgill.ca

$\dagger$ Electronic supplementary information (ESI) available. See DOI: 10.1039/c9sc00595a. temperature $\left(200^{\circ} \mathrm{C}\right)$ and large excess amounts of ammonia gas and hydrogen gas with a very limited substrate scope (phenol and $o / \mathrm{m} / \mathrm{p}$-cresols); and at relatively lower temperature, this transformation suffered from both low conversion of phenol and poor selectivity towards the primary aniline, which can be attributed to the weak nucleophilicity of ammonia and the low stability of the cyclohexylimine intermediate. Such an intermediate is prone to undergo a reduction process to form cyclohexylamine under reductive conditions. ${ }^{9}$ Therefore, a general and relatively mild phenol to primary aniline transformation is yet to be developed.

Hydrazine, as the simplest diamine, is an inexpensive, widely available and easy-to-handle amine source. ${ }^{10}$ It possesses stronger nucleophilicity than ammonia due to the $\alpha$-effect of the hydrazine nitrogen atom; ${ }^{11}$ moreover, the corresponding cyclohexanone hydrazone is isolatable and more stable than

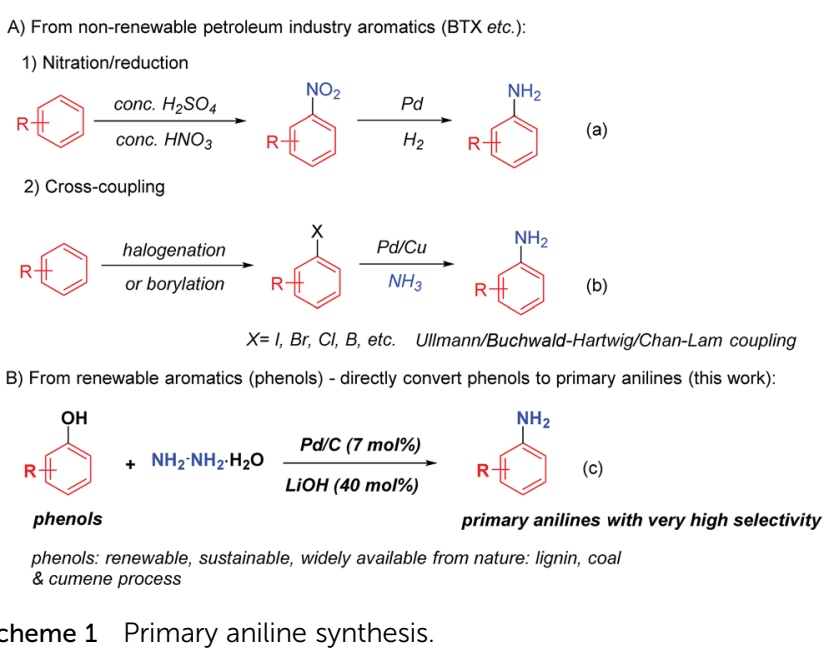


cyclohexylimine. ${ }^{\mathbf{1 2}}$ Previously, our group utilized hydrazine as the amine source to couple with phenols to generate various $N$ cyclohexylanilines, in which the acid protonated the formation of cyclohexanone hydrazone intermediate and facilitated its reduction to the cyclohexylamines. ${ }^{13}$ With our previous successes to couple phenols with various substituted amines ${ }^{\mathbf{1 4}}$ and hydrazine to produce $N$-substituted anilines, ${ }^{\mathbf{1 3}, \mathbf{1 4}}$ we contemplated the possibility of switching the phenol-hydrazine coupling selectivity towards primary anilines instead. We hypothesized that under less acidic or even basic conditions, the initial reduction of the cyclohexanone hydrazone intermediate might be slowed down. Instead, such a stable hydrazone intermediate could undergo the dehydrogenation process to rearomatize to phenylhydrazine with the catalysis of $\mathrm{Pd} / \mathrm{C}$, and then upon the reductive cleavage of the $\mathrm{N}-\mathrm{N}$ bond of the phenylhydrazine intermediate, the primary aniline could be generated in a highly selective fashion (Scheme 1c).

To examine the feasibility of our hypothesis, we initially tested the reaction using phenol with 1.5 equiv. hydrazine monohydrate, $10 \mathrm{~mol} \% \mathrm{Pd} / \mathrm{C}$ as the catalyst, and $50 \mathrm{~mol} \%$ $\mathrm{NaBH}_{4}$ as the hydride source in 1,4-dioxane $(0.2 \mathrm{M})$ at $150{ }^{\circ} \mathrm{C}$ for $12 \mathrm{~h}$ (Table 1, entry 1). To our delight, the desired primary aniline 3 a could be obtained in $10 \%$ yield; however, the selectivity was poor with $46 \% \mathrm{~N}$-cyclohexylaniline (4) as the main product along with $16 \%$ dicyclohexylamine, $1 \% \mathrm{~N}$-phenylaniline (5), some cyclohexane and benzene. We attributed the poor selectivity to the water molecule in the hydrazine monohydrate reagent, playing the role of a weak Brønsted acid to facilitate the reduction of the cyclohexanone hydrazone intermediate to generate cyclohexylamine, as our group discovered previously. ${ }^{13}$ To remove the water, various molecular sieves were investigated (Table S1 $\dagger$ ) and among them, the $4 \AA$ molecular sieves showed the best efficiency, increasing the yield of the primary aniline $\mathbf{3 a}$ to $58 \%$ (Table 1 , entry 2 ). The solvent had a significant effect on this transformation (Table $\mathrm{S} 2 \dagger$ ): for example, switching the solvent from 1,4-dixoane to toluene decreased the primary aniline 3 a yield to $43 \%$ along with a lower conversion of phenol (Table 1, entry 3 ). Various catalysts were then examined (Table S3 $\dagger$ ) and the Pd/C (5 wt\%) catalyst showed the best selectivity and highest yield of primary aniline 3a among $\mathrm{Pd} / \mathrm{C}(10 \mathrm{wt} \%), \mathrm{Pd} / \mathrm{Al}_{2} \mathrm{O}_{3}(5 \mathrm{wt} \%)$ and $\mathrm{Ru} / \mathrm{C}(5 \mathrm{wt} \%)$.

To help the tautomerization process of the cyclohexanone hydrazone intermediate, ${ }^{15}$ catalytic amounts of Brønsted and Lewis acids were tested (Table $\mathrm{S} 4 \dagger$ ), however, leading to a decreased yield of primary aniline $\mathbf{3 a}$ with an increased yield of $\mathrm{N}$-cyclohexylaniline (4) (Table 1, entries 4 and 5). Conversely, with the basic additives (Table $S 5 \dagger$ ), the yield of primary aniline 3a remained almost unchanged (Table 1, entries 6 and 7). To increase the selectivity of primary aniline $\mathbf{3 a}$ over $\mathrm{N}$-cyclohexylaniline (4), a gentler hydride donor might be needed, since a stronger hydride donor would favor the reduction of the cyclohexanone hydrazone intermediate towards the undesired cyclohexylamine intermediate. Hydrazine, on the other hand,

Table 1 Optimization of the reaction conditions ${ }^{a}$

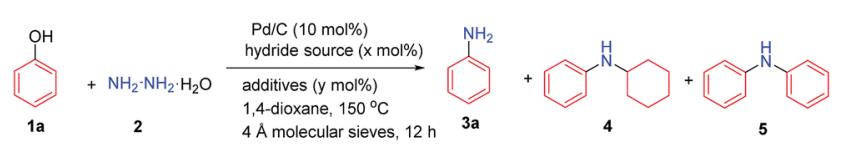

\begin{tabular}{|c|c|c|c|c|c|c|}
\hline $1^{b}$ & $\mathrm{NaBH}_{4}(50)$ & - & 100 & 10 & 46 & \\
\hline $3^{c}$ & $\mathrm{NaBH}_{4}(50)$ & - & 81 & 43 & 8 & $1<$ \\
\hline 4 & $\mathrm{NaBH}_{4}(50)$ & $\mathrm{ZnF}_{2}(10)$ & 100 & 30 & 36 & 11 \\
\hline 5 & $\mathrm{NaBH}_{4}(50)$ & HOAc (10) & 81 & 41 & 12 & 3 \\
\hline 8 & - & - & 67 & 25 & 4 & 10 \\
\hline $9^{j}$ & - & - & 78 & 51 & 2 & 2 \\
\hline $10^{k}$ & - & - & 82 & 49 & 2 & 2 \\
\hline $11^{e}$ & $\mathrm{HCO}_{2} \mathrm{Na}(1.0)$ & - & 100 & 64 & 3 & $1<$ \\
\hline $12^{e}$ & $\mathrm{HCO}_{2} \mathrm{Na}(1.0)$ & $\mathrm{LiOH}(40)$ & 100 & 68 & 2 & $1<$ \\
\hline $13^{f}$ & $\mathrm{HCO}_{2} \mathrm{Na}(1.0)$ & $\mathrm{LiOH}(40)$ & 100 & 69 & 4 & 2 \\
\hline
\end{tabular}

${ }^{a}$ Reaction conditions: phenol ( $0.2 \mathrm{mmol}, 1$ equiv.), $\mathrm{N}_{2} \mathrm{H}_{4} \cdot \mathrm{H}_{2} \mathrm{O}$ ( $0.3 \mathrm{mmol}, 1.5$ equiv.), $10 \mathrm{~mol} \%$ of 5 wt\% Pd/C, various hydride sources, and additives with $4 \AA$ A molecular sieves (100 mg per $0.3 \mathrm{mmol}$ hydrazine) in 1,4-dioxane $(0.2 \mathrm{M})$ were stirred under argon for $12 \mathrm{~h}$; starting material conversions and NMR yields were given with 1,3,5-trimethoxylbenzene as the internal standard, and yields were calculated based on phenol. ${ }^{b}$ No molecular sieves were added. ${ }^{c}$ Toluene was used as the solvent instead of 1,4 -dioxane. ${ }^{d} 3.0$ equiv. $\mathrm{N}_{2} \mathrm{H}_{4} \cdot \mathrm{H}_{2} \mathrm{O}$ was used. ${ }^{e} 3.0$ equiv. $\mathrm{N}_{2} \mathrm{H}_{4}$ in THF solution $(1 \mathrm{M})$ was used. ${ }^{f} 2.25$ equiv. $\mathrm{N}_{2} \mathrm{H}_{4}$ in THF solution $(1 \mathrm{M})$ was used. ${ }^{g}$ Reaction was run at $170{ }^{\circ} \mathrm{C} .{ }^{h} 7 \mathrm{~mol} \% \mathrm{Pd} / \mathrm{C}$ was used. ${ }^{i} 0.4$ mmol phenol was used. ${ }^{j} 4.5$ equiv. $\mathrm{N}_{2} \mathrm{H}_{4} \cdot \mathrm{H}_{2} \mathrm{O}$ was used. ${ }^{k} 6.0$ equiv. $\mathrm{N}_{2} \mathrm{H}_{4} \cdot \mathrm{H}_{2} \mathrm{O}$ was used. ${ }^{l}$ Isolated yield. For details of optimization (Tables S1-S12), please see the ESI; HOAc = acetic acid. 
might slowly decompose to $\mathrm{H}_{2}$ in situ under the $\mathrm{Pd} / \mathrm{C}$ catalyst, and thus could also serve as a slowly generating mild hydride source. ${ }^{10}$ To test this postulation, a control experiment without $\mathrm{NaBH}_{4}$ was carried out, in which the primary aniline 3a was generated in $25 \%$ yield (Table 1 , entry 8 ). By increasing the amount of hydrazine to 4.5 equiv., the yield of primary aniline 3 a could be increased to $51 \%$ with slightly increased conversion and better 3a selectivity (Table 1, entry 9 vs. 8); however, no further improvement was observed when increasing the hydrazine amount to 6 equiv. (Table 1, entry 10).
To increase the conversion of phenol, small amounts of various hydride donors were added (Table S8, $\uparrow$ entries 5-9) and finally by using the relatively weak hydride donor $\mathrm{HCO}_{2} \mathrm{Na}$ and with 3 equiv. of hydrazine in THF $(1 \mathrm{M})$, the yield of primary aniline 3a could be slightly increased to 64\% (Table 1, entry 11 vs. 2). When $\mathrm{LiOH}$ was added to the reaction system, the desired primary aniline 3a yield could be slightly increased to $68 \%$ (Table 1, entry 12), ${ }^{10}$ and decreasing the hydrazine amount from 3.0 equiv. to 2.25 equiv. maintained the same efficiency, generating the primary aniline $3 \mathbf{a}$ in $69 \%$ yield (Table 1, entry

Table 2 Substrate scope of phenols ${ }^{a}$

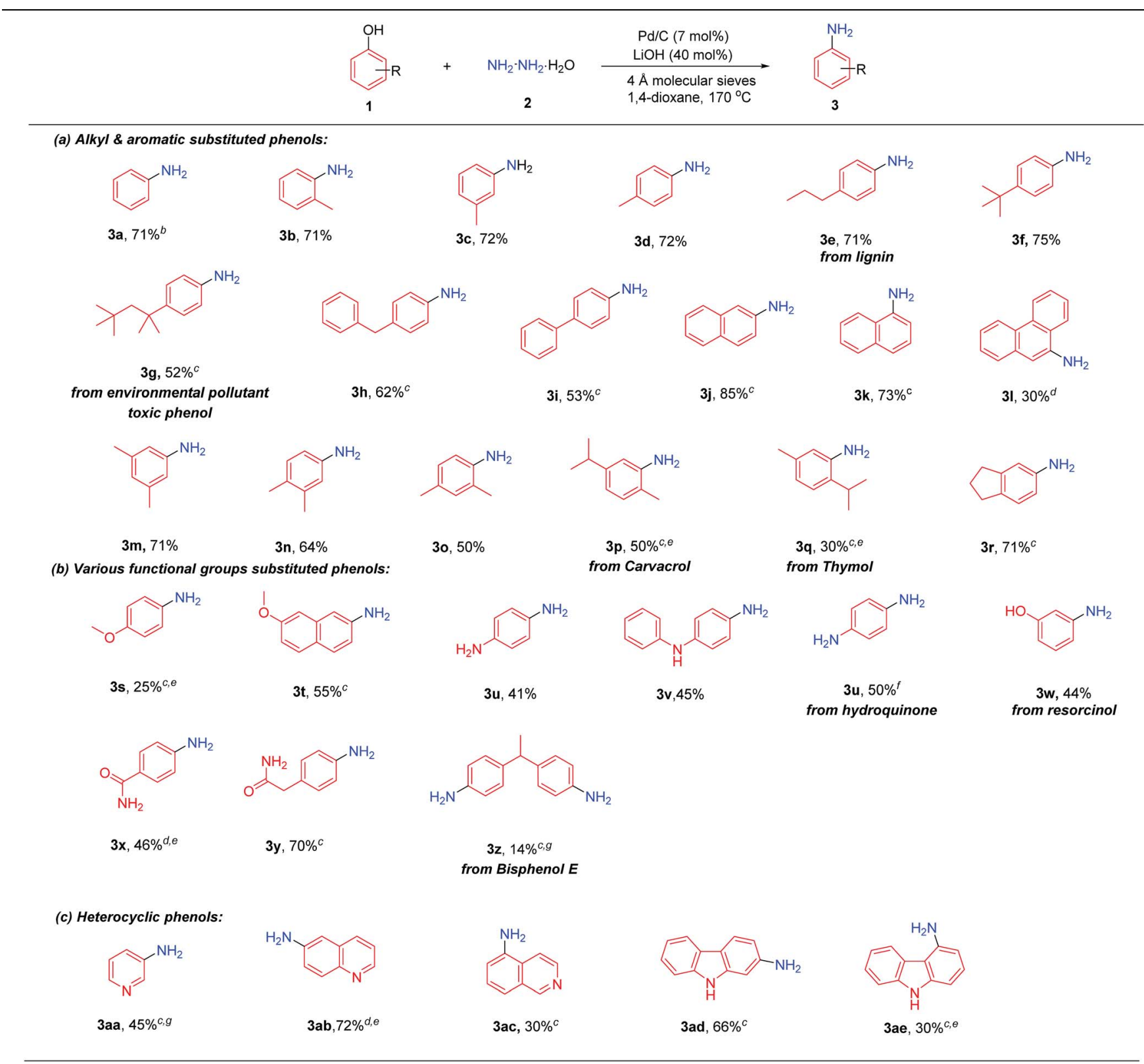

${ }^{a}$ Reaction conditions: phenols ( $0.4 \mathrm{mmol}, 1$ equiv.), $\mathrm{N}_{2} \mathrm{H}_{4} \cdot \mathrm{H}_{2} \mathrm{O}(1.8 \mathrm{mmol}, 4.5$ equiv.), $7 \mathrm{~mol} \%$ of $5 \mathrm{wt} \% \mathrm{Pd} / \mathrm{C}$ and 4 A molecular sieves (100 mg per $0.3 \mathrm{mmol}$ hydrazine) in 1,4-dioxane $(0.2 \mathrm{M})$ were stirred under argon for $16 \mathrm{~h}$; isolated yields were given. ${ }^{b} 3$ equiv. $\mathrm{N}_{2} \mathrm{H}_{4} \cdot \mathrm{H}_{2} \mathrm{O}$ was used and reaction was run for 12 h. $^{c} 37.5 \mathrm{~mol} \% \mathrm{NaBH}_{4}$ was added. ${ }^{d} 50 \mathrm{~mol} \% \mathrm{NaBH}_{4}$ was added. ${ }^{e} \mathrm{LiOH}$ was not added. ${ }^{f} 5$ equiv. $\mathrm{N}_{2} \mathrm{H}_{4} \cdot \mathrm{H}_{2} \mathrm{O}$ was used. ${ }^{g} 20$ mol\% of $5 \mathrm{wt} \% \mathrm{Pd} / \mathrm{C}$ was used. 
13). Other metal hydroxides also showed positive effects on the primary aniline 3a formation but were all inferior to $\mathrm{LiOH}$ (Table S9, $\dagger$ entries 18-21), while other lithium salts exhibited negative effects (Table S9, $\uparrow$ entries 8-14). By elevating the temperature to $170{ }^{\circ} \mathrm{C}$ and with the $\mathrm{Pd} / \mathrm{C}$ catalyst loading decreased to $7 \mathrm{~mol} \%$, the primary aniline $3 \mathbf{a}$ yield could be increased to $72 \%$ (Table 1 , entry 14 ) probably due to the balanced rate of dehydrogenation and hydrogenation processes. Fortunately, by carefully tuning the reaction conditions, we found that with 3.0 equiv. hydrazine monohydrate and $40 \mathrm{~mol} \% \mathrm{LiOH}$ without any extra hydride donor at $170{ }^{\circ} \mathrm{C}$, the primary aniline $3 \mathrm{a}$ could be produced in $71 \%$ isolated yield with excellent selectivity (Table 1, entry 15 and Table S11 $\dagger$ ), in which the hydrazine acted as both the amine and hydride sources.

With the optimized conditions in hand, the substrate scope of phenols was investigated. As shown in Table 2, phenols bearing various alkyl and aromatic substituents reacted smoothly to afford the corresponding primary aromatic amines $\mathbf{3 b}-\mathbf{3 r}$ in moderate to excellent yields. 4-Propylphenol, as one of the predominant products derived from lignin, ${ }^{7 b}$ could generate the corresponding 4-propylaniline (3e) in a good yield $(71 \%)$ under the standard conditions. Sterically bulky substituted phenols, such as 4-tert-butylphenol and 4tert-octylphenol (a potential environmental pollutant exhibiting toxic and estrogenic effects), could afford products $3 \mathbf{f}$ and $\mathbf{3 g}$ efficiently. 2-Naphthol and 1-naphthol gave the corresponding naphthylamines $\mathbf{3 j}$ and $\mathbf{3 k}$ in $85 \%$ and $73 \%$ yield, respectively, while 9-phenanthrol afforded product 31 in relatively lower yield. Disubstituted phenols also worked well in this reaction: 3,5-, 3,4- and 2,4-dimethyl phenols all produced disubstituted anilines $\mathbf{3 m - 3 0}$ in $50-71 \%$ yields, while 2,4dimethylphenol gave relatively lower yield due to the steric hindrance of the ortho methyl group. Carvacrol and thymol, both naturally abundant bioactive monoterpenic phenols, could successfully be converted into the corresponding anilines; the higher yield with carvacrol than thymol is likely due to the higher steric hindrance of the isopropyl group than that of the methyl group (3p vs. 3q). 5-Indanol, consisting of a 5-membered fused cyclic ring with phenol, gave a good yield of product $3 \mathbf{r}$.

Next, the scope of phenols with various functional substituents was examined (3s-3z). 4-Methoxylphenol afforded 4methoxylaniline (3s) in low yield, together with some C-OMe bond cleavage products, while 7-methoxy-2-naphthol gave product 3t in relatively higher yield. 4-Amino phenol reacted smoothly to generate 1,4-diaminophenol (3u) without the need of pre-protection of the amino group. Dihydroxyl-benzene could react well in this transformation, in which both hydroxyl groups of 1,4-dihydroxylbenzene (hydroquinone) would react to generate 1,4-diaminobenzene, whereas for 1,3-dihydroxylbenzene (resorcinol), one hydroxyl group reacted to give 3aminophenol (3w) selectively. A phenol bearing an amide substituent gave the product $3 x$ in $46 \%$ yield, whereas when 2(4-hydroxyphenyl)acetamide was tested, the aniline product $\mathbf{3 y}$ could be obtained in $70 \%$ yield. The bisphenol type compound could also undergo this transformation, although in lower yield $(3 z)$.

Finally, the scope of heterocyclic phenols was investigated (3aa-3ae). 3-Aminopyridine (3aa) could be directly obtained from 3-hydroxypyridine in moderate yield. Besides, 6-aminoquinoline (3ab) (used as an internal standard in determining serum nicotine $)^{\mathbf{1 6}}$ was obtained in high yield, while 5-aminoisoquinoline (3ac) was generated in lower yield. Hydroxyl substituted carbazoles were also suitable substrates for this reaction, with 2-hydroxycarbazole giving higher yield than 4hydroxycarbazole possibly because of the steric hindrance of 5$\mathrm{H}$ in 4-hydroxycarbazole (3ad vs. 3ae). Unfortunately, when the lignin monomers were directly used as starting materials, the desired primary aniline products could not be obtained (for details, please see the ESI $\dagger$ ).

To evaluate the synthetic potential of this direct conversion of phenols to primary anilines, several useful primary anilines applied in pharmaceuticals and organometallic chemistry were directly synthesized from the corresponding phenols (Scheme 2). Benzocaine (3af) (a pharmaceutical drug for oral ulcers and a local anesthetic), 4-aminopyridine (3ag)
Synthetic applications of this method:
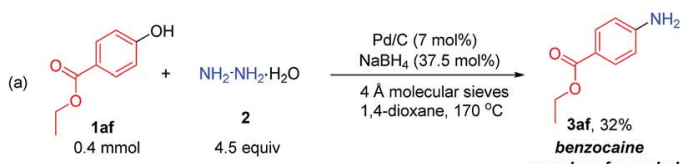

benzocaine

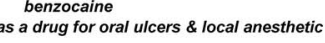

(b)
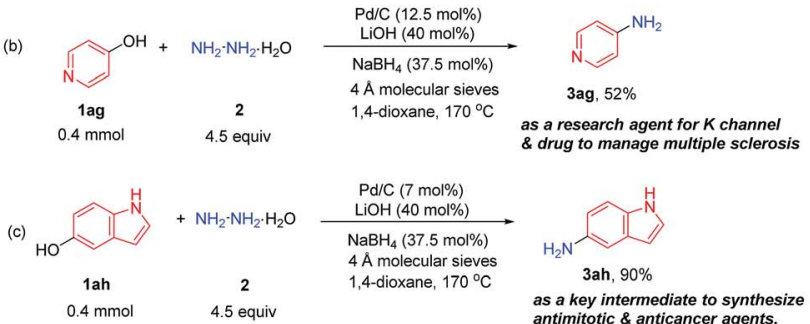

$\mathrm{Pd} / \mathrm{C}(7 \mathrm{~mol} \%)$ $\mathrm{NaBH}_{4}(37.5 \mathrm{~mol} \%)$ $4 \AA$ molecular sieves

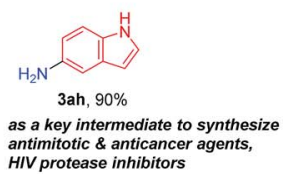

(d)
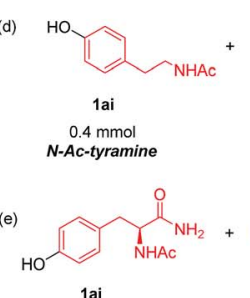

1 aj
$0.4 \mathrm{mmol}$

Ac-Tyr- $\mathrm{NH}_{2}$

(f)

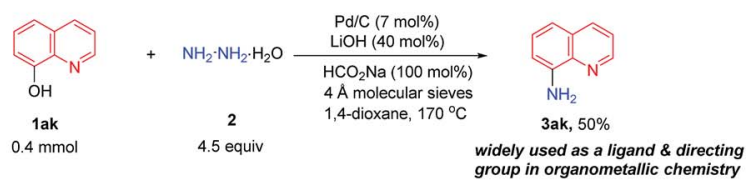

Scheme 2 Synthetic applications. 

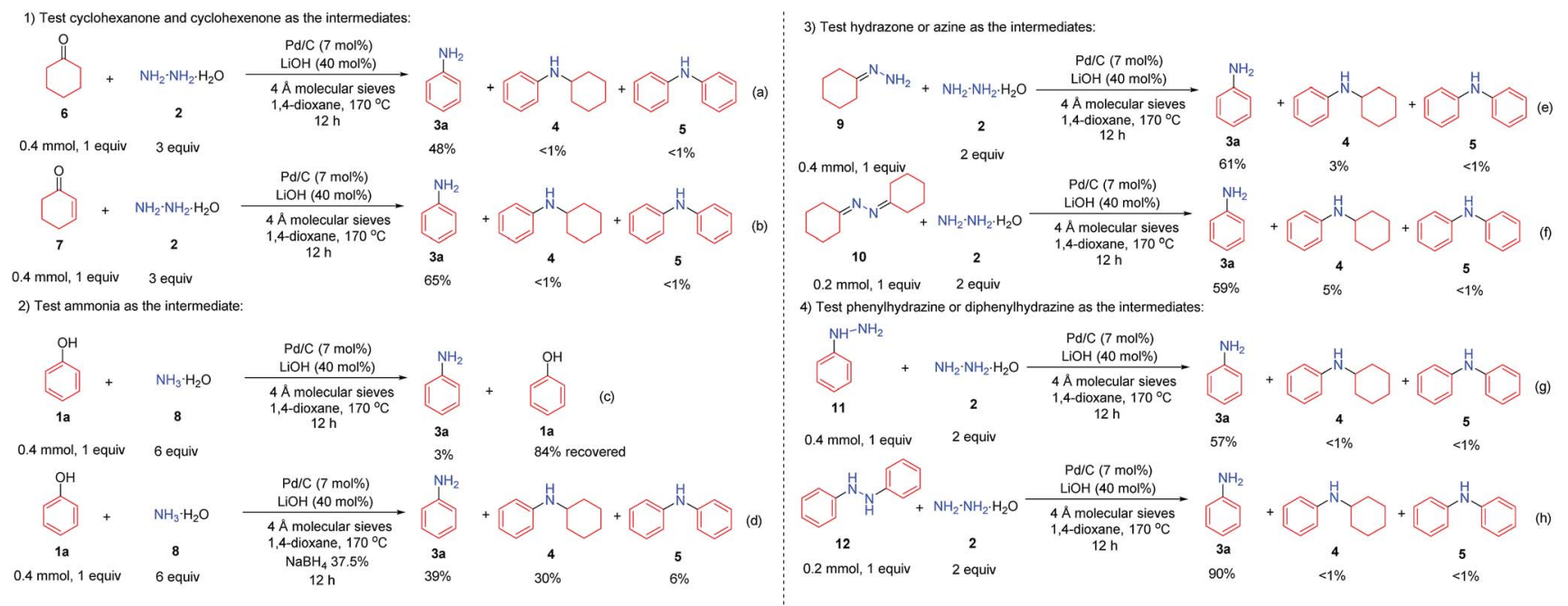

Scheme 3 Studies of reaction mechanism.

(used as a research agent to characterize potassium channels and a drug to manage multiple sclerosis ${ }^{17}$ ) and 5 -aminoindole (3ah) (used as a key intermediate to prepare antimitotic and anticancer agents and HIV protease inhibitors ${ }^{18}$ ) could all be obtained in moderate to high yields directly from phenols (Scheme 2a-c). Moreover, protected tyrosine (amino acid) and tyramine (the decarboxylation product from tyrosine) were all suitable substrates for this reaction (3ai and 3aj) to afford the corresponding aniline analogues in one step (Scheme $2 \mathrm{~d}$ and e). Besides, 8-aminoquinoline (3ak), which is widely used as a ligand and directing group in organometallic chemistry, ${ }^{19}$ was also produced efficiently in this transformation (Scheme 2f).

The plausible mechanism was investigated (Scheme 3). First, cyclohexanone (6) and cyclohexenone (7), as the two possible reduced forms of phenol, were reacted with hydrazine under the standard conditions, and both reactions afforded the desired primary aniline product $3 \mathbf{a}$ (in $48 \%$ and $65 \%$ yields, respectively) with excellent selectivity (Scheme $3 a$ and $b$ ), indicating the possible involvement of both cyclohexanone (6) and cyclohexenone (7) as the reaction intermediates. Second, since hydrazine might decompose to ammonia under the current $\mathrm{Pd} / \mathrm{C}$ catalyst system,${ }^{10}$ ammonia was used as the amine source to react with phenol (1a) as the control experiments (Scheme $3 \mathrm{c}$ and d). Without additional hydride sources, phenol (1a) was mainly recovered in $84 \%$ yield (Scheme 3c), whereas in the presence of a small amount of $\mathrm{NaBH}_{4}$, the primary aniline was generated in $39 \%$ yield but with poor selectivity (Scheme 3d), showing the unlikely involvement of ammonia as the intermediate. Third, the two possible intermediates hydrazone $\mathbf{9}$ and azine $\mathbf{1 0}$ were tested (Scheme 3e and f). Both of them could generate the primary aniline 3a with good yield and selectivity under standard conditions, demonstrating that they are possible intermediates in this transformation. Finally, the possible intermediates phenylhydrazine $\mathbf{1 1}$ and diphenylhydrazine $\mathbf{1 2}$ were examined (Scheme $3 \mathrm{~g}$ and $\mathrm{h}$ ): in both cases, the desired primary aniline 3a could be obtained in good yield and very high selectivity, indicating that both would be the possible intermediates involved in this transformation.

Based on the above mechanistic studies and literature reports, a tentative mechanism for this direct phenol to primary aniline reaction is proposed in Scheme 4 . Initially, $\operatorname{HPd}^{\mathrm{II}} \mathrm{H}$ (palladium hydride) species can be generated either by the decomposition of $\mathrm{N}_{2} \mathrm{H}_{4}$ under the $\mathrm{Pd} / \mathrm{C}$ catalyst ${ }^{10}$ or by $\mathrm{NaBH}_{4}$ reacting with $\mathrm{Pd} / \mathrm{C}$ in the cases that $\mathrm{NaBH}_{4}$ is added. ${ }^{14 c, e}$ The palladium hydride then reduces the phenol (1a) to cyclohexanone or cyclohexenone intermediate $\mathbf{I} .^{14 a, c}$ Then, intermediate $\mathbf{I}$ can condense with hydrazine to afford the hydrazone or azine intermediate II, which is followed by the hydrazone-enehydrazine tautomerization to generate intermediate III. ${ }^{15}$ Then intermediate III can readily undergo dehydrogenation and rearomatize to form the phenylhydrazine type intermediate IV, and meanwhile regenerate the $\mathrm{HPd}^{\mathrm{II}} \mathrm{H}$ species. ${ }^{14 a, c, e}$ Finally, reductive $\mathbf{N}-\mathbf{N}$ bond cleavage of $\mathbf{I V}^{20}$ produces the desired

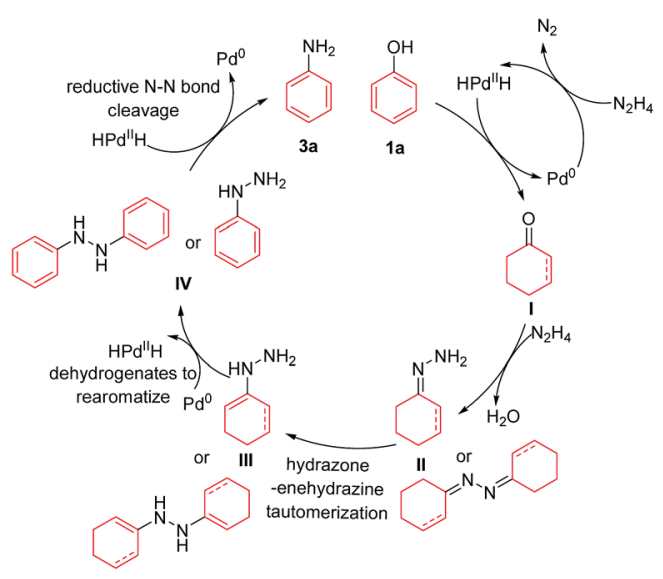

Scheme 4 Tentative mechanism. 
primary aniline product $\mathbf{3 a}$ and regenerates the $\mathrm{Pd}^{0}$ species at the same time.

\section{Conclusions}

In conclusion, we have developed a general method to directly convert a wide range of naturally abundant and renewable phenols into the corresponding primary anilines with the cheap and easy-to-handle hydrazine, acting as both amine and hydride sources, under relatively mild conditions with simple $\mathrm{Pd} / \mathrm{C}$ as the catalyst. Bio-active phenols, such as carvacrol, thymol, hydroquinone, resorcinol, tyrosine and tyramine derivatives, are all appropriate substrates in this transformation and moreover, some useful primary anilines (shown in Scheme 2) could be directly synthesized by this protocol as well. Ongoing studies of other direct phenol amination methods are underway in our laboratory.

\section{Conflicts of interest}

There are no conflicts to declare.

\section{Acknowledgements}

We are grateful to the Canada Research Chair Foundation (to C.J. Li), the CFI, FQRNT Center for Green Chemistry and Catalysis, NSERC, and McGill University for supporting our research.

\section{Notes and references}

1 (a) S. A. Lawrence, Amines: Synthesis, Properties and Applications, Cambridge University Press, 2004; (b) T. Kahl, K. W. Schröder, F. Lawrence, W. Marshall, H. Höke and R. Jäckh, Aniline, in Ullmann's Encyclopedia of Industrial Chemistry, 2012, ch. 465, vol. 3, pp. 465-477; (c) J. Schranck and A. Tlili, ACS Catal., 2018, 8, 405-418.

2 G. Alfke, W. W. Irion and O. S. Neuwirth, Oil Refining, in Ullmann's Encyclopedia of Industrial Chemistry, 2007, vol. 25, pp. 208-261.

3 J. F. Hartwig, S. Shekhar, Q. Shen and F. Barrios-Landeros, Synthesis of Anilines in the Chemistry of Anilines, 2007, pp. 455-536.

4 M. B. Smith and J. March, Electrophilic Aromatic Substitution, in March's Advanced Organic Chemistry, 2006, ch. 11, pp. 657-751.

5 (a) J. F. Hartwig, Chem. Soc. Rev., 2011, 40, 1992-2002; (b) T. M. Boller, J. M. Murphy, M. Hapke, T. Ishiyama, N. Miyaura and J. F. Hartwig, J. Am. Chem. Soc., 2005, 127, 14263-14278.

6 (a) N. Xia and M. Taillefer, Angew. Chem., Int. Ed., 2009, 48, 337-339; (b) M. Fan, W. Zhou, Y. Jiang and D. Ma, Org. Lett., 2015, 17, 5934-5937; (c) Q. Shen and J. F. Hartwig, J. Am. Chem. Soc., 2006, 128, 10028-10029; (d) D. S. Surry and S. L. Buchwald, J. Am. Chem. Soc., 2007, 129, 10354-10355; (e) H. Rao, H. Fu, Y. Jiang and Y. Zhao, Angew. Chem., Int. Ed., 2009, 48, 1114-1116; For recent advances in primary aniline synthesis, please see: $(f)$ L. Legnani, G. P. Cerai and
B. Morandi, ACS Catal., 2016, 6, 8162-8165; (g) J. Liu, K. Wu, T. Shen, Y. Liang, M. Zou, Y. Zhu, X. Li, X. Li and N. Jiao, Chem.-Eur. J., 2017, 23, 563-567; (h) X. Jin, Y. Koizumi, K. Yamaguchi, K. Nozaki and N. Mizuno, J. Am. Chem. Soc., 2017, 139, 13821-13829; (i) J. Liu, X. Qiu, X. Huang, X. Luo, C. Zhang, J. Wei, J. Pan, Y. Liang, Y. Zhu, Q. Qin, S. Song and N. Jiao, Nat. Chem., 2019, 11, 71-77. For a recent work on conversion of aliphatic $\mathrm{OH}$ to $\mathrm{NH}_{2}$, please see: (j) W. Deng, Y. Wang, S. Zhang, K. M. Gupta, M. J. Hulsey, H. Asakura, L. Liu, Y. Han, E. M. Karp, G. T. Beckham, P. J. Dyson, J. Jiang, T. Tanaka, Y. Wang and N. Yan, Proc. Natl. Acad. Sci. U. S. A., 2018, 115, 5093-5098.

7 (a) B. M. Upton and A. M. Kasko, Chem. Rev., 2016, 116, 22752306; (b) C. Li, X. Zhao, A. Wang, G. W. Huber and T. Zhang, Chem. Rev., 2015, 115, 11559-11624; (c) G. W. Huber and A. Corma, Angew. Chem., Int. Ed., 2007, 46, 7184-7201; (d) M. Weber, M. Weber and M. Kleine-Boymann, Phenol, in Ullmann's Encyclopedia of Industrial Chemistry, 2012, ch. 503, vol. 26, pp. 503-518.

8 H. Zeng, Z. Qiu, A. Domínguez-Huerta, Z. Hearne, Z. Chen and C.-J. Li, ACS Catal., 2016, 7, 510-519.

9 T. Cuypers, P. Tomkins and D. E. De Vos, Catal. Sci. Technol., 2018, 8, 2519-2523.

10 (a) J.-P. Schirmann and P. Bourdauducy, Hydrazine, in Ullmann's Encyclopedia of Industrial Chemistry, 2001, vol. 18, pp. 79-96; (b) L. He, B. Liang, Y. Huang and T. Zhang, Natl. Sci. Rev., 2017, 5, 356-364; (c) A. Furst, R. C. Berlo and S. Hooton, Chem. Rev., 1965, 65, 51-68.

11 (a) T. A. Nigst, A. Antipova and H. Mayr, J. Org. Chem., 2012, 77, 8142-8155; (b) J. O. Edwards and R. G. Pearson, J. Am. Chem. Soc., 1962, 84, 16-24.

12 (a) P. Rulliere, G. Benoit, E. M. D. Allouche and A. B. Charette, Angew. Chem., Int. Ed., 2018, 57, 5777-5782; (b) D. K. Kolmel and E. T. Kool, Chem. Rev., 2017, 117, 10358-10376.

13 J.-S. Li, Z. Qiu and C.-J. Li, Adv. Synth. Catal., 2017, 359, 36483653.

14 (a) Z. Chen, H. Zeng, S. A. Girard, F. Wang, N. Chen and C.-J. Li, Angew. Chem., Int. Ed., 2015, 54, 14487-14491; (b) Z. Chen, H. Zeng, H. Gong, H. Wang and C.-J. Li, Chem. Sci., 2015, 6, 4174-4178; (c) Z. Qiu, J.-S. Li and C.-J. Li, Chem. Sci., 2017, 8, 6954-6958; (d) A. Dominguez-Huerta, I. Perepichka and C.-J. Li, Communications Chemistry, 2018, 1, 45; (e) H. Zeng, D. Cao, Z. Qiu and C.-J. Li, Angew. Chem., Int. Ed., 2018, 57, 3752-3757; $(f)$ D. Cao, H. Zeng and C.-J. Li, ACS Catal., 2018, 8, 8873-8878; $(g)$ S. A. Girard, X. Hu, T. Knauber, F. Zhou, M. O. Simon, G.-J. Deng and C.-J. Li, Org. Lett., 2012, 14, 5606-5609.

15 (a) F. Zhan and G. Liang, Angew. Chem., Int. Ed., 2013, 52, 1266-1269; (b) J. J. Li, Fischer indole synthesis in Name Reactions, Springer International Publishing, Cham, 5th edn, 2014, pp. 253-254; (c) N. D. Heindel, P. d. Kennewel and M. Pfau, J. Org. Chem., 1970, 35, 80-83.

16 P. J. Aragon, A. D. Yapi, F. Pinguet, J. M. Chezal, J. C. Teulade, J. P. Chapat and Y. Blache, Chem. Pharm. Bull., 2004, 52, 659663. 
17 (a) H. B. Jensen, M. Ravnborg, U. Dalgas and E. Stenager, Ther. Adv. Neurol. Disord., 2014, 7, 97-113; (b) L. S. Chin, C. C. Park, K. M. Zitnay, M. Sinha, A. J. DiPatri Jr., P. Perillan and J. M. Simard, J. Neurosci. Res., 1997, 48, 122-127.

18 (a) V. Gasparotto, I. Castagliuolo, G. Chiarelotto, V. Pezzi, D. Montanaro, P. Brun, G. Palu, G. Viola and M. G. Ferlin, J. Med. Chem., 2006, 49, 1910-1915; (b) L. D. Via, O. Gia, V. Gasparotto and M. G. Ferlin, Eur. J. Med. Chem., 2008, 43, 429-434; (c) L. Chiummiento, M. Funicello,
P. Lupattelli, F. Tramutola and P. Campaner, Tetrahedron, 2009, 65, 5984-5989.

19 (a) M. Corbet and F. De Campo, Angew. Chem., Int. Ed., 2013, 52, 9896-9898; (b) H. Hudali, J. Kingston and H. Tayim, Inorg. Chem., 1979, 18, 1391-1394.

20 (a) A. Gevorgyan, S. Mkrtchyan, T. Grigoryan and V. O. Iaroshenko, Chempluschem, 2018, 83, 375-382; (b) F. Alonso, P. Candela, C. Gómez and M. Yus, Adv. Synth. Catal., 2003, 345, 275-279. 